Portland State University

PDXScholar

7-1-2013

\title{
Defining and Characterizing Open Peer Review: A Review of the Literature
}

\author{
Emily Ford \\ Portland State University, forder@pdx.edu
}

Follow this and additional works at: https://pdxscholar.library.pdx.edu/ulib_fac

Part of the Library and Information Science Commons Let us know how access to this document benefits you.

\section{Citation Details}

Ford, Emily, "Defining and Characterizing Open Peer Review: A Review of the Literature" (2013). Library Faculty Publications and Presentations. 1.

https://pdxscholar.library.pdx.edu/ulib_fac/1

This Post-Print is brought to you for free and open access. It has been accepted for inclusion in Library Faculty Publications and Presentations by an authorized administrator of PDXScholar. Please contact us if we can make this document more accessible: pdxscholar@pdx.edu. 


\title{
Defining and Characterizing Open Peer Review: A review of the literature
}

\section{Emily Ford}

Emily Ford is Assistant Professor and Urban \& Public Affairs Librarian at Portland State University in Portland, Oregon.

\begin{abstract}
Changes in scholarly publishing have resulted in a move toward openness. To this end, new, open models of peer review are emerging. While the scholarly literature has examined and discussed open peer review, no established definition of it exists, nor are there uniform implementations of open peer review processes. This article examines the literature discussing open peer review, identifies common open peer review definitions, and describes eight common characteristics of open peer review: signed review, disclosed review, editor-mediated review, transparent review, crowdsourced review, prepublication review, synchronous review, and post-publication review. This article further discusses benefits and challenges to the scholarly publishing community posed by open peer review, and concludes that open peer review can and should exist within the current scholarly publishing paradigm.
\end{abstract} Keywords: peer review, open peer review, literature review, scholarly communication

\section{Introduction}

Over the last twenty years the landscape of scholarly publishing has changed as a result of technological innovation. So has its quality control process, peer review. The scholarly community is questioning whether journals need to publish in print and if volume and issue numbers are necessary. As a result, discussions about "opening up" scholarly publishing and peer review processes have 
evolved. Where would peer review fit into a newfound ethos of openness? Is traditional double blind peer review the best system? How could we open the peer review process?

As early as 1988 Michael McGiffert investigated whether the double blind peer review system should be opened. Results of his survey of 100 referees for The William \& Mary Quarterly revealed that while some referees would be willing to disclose their identities, the majority wished the process to remain blind. ${ }^{1}$ During the nineties, scholars began to embrace alternative peer review models. In their 1996 article, 'Open Peer Review \& Argumentation,' Tamara Sumner and Buckingham Shum outlined their plans for the Journal for Interactive Media in Education. ${ }^{2}$ Their proposal relied on the web to mediate and open up the Journal's review process.

Changes in peer review are imminent and scholarship regarding peer review is continually emerging. In this literature review I investigate the scholarly dialogue regarding open peer review, discuss definitions of open peer review, and identify open peer review characteristics. Further, I discuss the benefits and challenges that open peer review poses to scholarly communities. To end, I draw conclusions about what the literature reveals and suggest further research that will lead to an improved understanding of open peer review.

\section{Methodology}

To find and aggregate the literature on open peer review I turned to the broad scope of academic literature, conducting literature searches in multidisciplinary databases such as Web of Science, Google Scholar, and Academic Search Complete, in addition to disciplinary databases in communication, sociology, and library and information science (LIS). I examined thirty-five articles published within the last ten years whose central theme was peer review of scholarly articles. I excluded articles discussing peer review of research funding and editorials. However, some exceptions in the sample set 
do remain, but only for articles where peer review was a central discussion of an article published more than ten years ago.

\section{Findings}

Article Demographics

Included articles represented a range of academic disciplines. In this set fifteen articles discussed open peer review occurring in the sciences, fourteen articles had an interdisciplinary focus, and seven articles discussed the humanities and social sciences. Twenty-four articles were published in journals aimed at LIS or publishing professionals, four articles were published in social sciences journals, and six were published in science journals. Five of the thirty-four were published in open access (OA) journals, including two of the LIS articles. The majority of articles (23) were authored by those with institutional affiliations outside of the United States, mostly from European countries. United States affiliated researchers authored twelve of the articles. Although the fields of LIS and scholarly publishing seem most interested in the topic of open peer review, it is surprising that such a small number of the articles were published in OA journals. However, the number of published articles discussing open peer review increases each year. Twenty of the thirty-four articles were published in 2010 or later.

I surmise that the demographics of open peer review will continue to change; we will see more articles discussing open peer review published in the humanities and social sciences, and that authors in the United States will start contributing more to the discussion. Moreover, as open access is more readily embraced by the scholarly community, the instances of open peer review will continue to increase. 
Unsurprisingly, there is no established definition of open peer review accepted by the scholarly research and publishing community. Disciplinary scholarship varies widely, as do disciplinary publishing practices; as a result, so do disciplines' definitions and treatments of open peer review. By far the most simple definition of open peer review is offered by Nancy McCormack, who discusses open peer review as a process that does not attempt '...to mask the identity of authors or reviewers. ${ }^{3}$ Similarly, Adrian Mulligan and his co-authors posit, 'Open Peer Review is where the reviewers' names and authors names are known to one another, and often also to the public at large. ${ }^{4}$ Mark Ware's literature review expands on peer review disclosure practices, contrasting them with double blind peer review: 'open peer reviews can mean the opposite of double blind, in which authors' and reviewers' identifies are both known to each other (and sometimes publicly disclosed), but discussion is complicated by the fact that it is also used to describe other approaches, such as where the reviewers remain anonymous but their reports are published..$^{5}$

For others, open peer review is distinctly defined. For example, David Shotton defines open peer review as a process that is completely transparent. 'The whole review process is entirely transparent. Each submitted manuscript is immediately made available on the journal's website. Reviews and comments from readers are welcomed, and are considered alongside the formal peer reviews solicited from experts by the journal. ${ }^{6}$ Despite the differing definitions and implementations of open peer review discussed in the literature its general treatment suggests that the process incorporates disclosure of authors' and reviewers' identities at some point during an article's review and publication.

\section{Characteristics of Open Peer Review}

Upon examination of the open peer review literature, it becomes clear that there exist several common open peer review characteristics. Five characteristics describe the openness of the review process: signed review, disclosed review, editor-mediated review, transparent review, and crowdsourced 
review. Three additional characteristics describe review timing, similar to traditional peer review: prepublication review, synchronous review, and post-publication review. Most open peer review implementations exhibit more than one openness characteristic, and may also exhibit more than one timing characteristic

First I will explain the characteristics, and then I will offer literature-based examples of these characteristics.

- Signed Review

Signed review refers to submitted reviews signed by the referee that are either published alongside articles at the time of publication, or are signed when an author receives them.

- Disclosed review

Disclosed review refers to a process in which referees and authors know each others' identities during the peer review process, enabling them to engage in discussion or discourse.

- Editor-mediated review

Editor-mediated review is a characteristic found in most open peer review processes. Editor mediation is any work done by a journal editor to facilitate open peer review. This may include editorial pre-selection of articles, and/or final decision-making for acceptance or rejection of articles. The editor-mediated portion of any open peer review process may or may not be publicly disclosed.

- Transparent Review

Transparent review refers to complete openness to a distinct community or the public. It allows a public community to watch peer review unfold. Authors and the public know referees' identities, and referees know authors' identities. Author responses to referee comments are public. In transparent review the public can see manuscripts, reviews, and replies from authors and public reviewers, as well as the published articles. 
- Crowdsourced review

Crowdsourced review is a public review process in which any community member may contribute to the article review. In crowdsourced review there is no limit to the number of comments or reviews an article may receive. In some proposed implementations of crowdsourced review there is little editorial mediation of article reviews. Rather, authors may simply submit papers to a pre-print server or other community for crowdsourced commentary.

- Pre-publication review

Pre-publication review occurs prior to article publication, and typically occurs in a public space such as a pre-print server.

- Synchronous review

Synchronous review occurs at the same time as publication of the article. In the literature, synchronous review is approached only theoretically, as part of a novel and completely iterative publishing model.

- Post-publication review

Post publication review occurs after an article is published, much like commentary on a blog post.

Signed review is one of the most common open peer review characteristics and is often paired with one or more additional peer review characteristics. Alan Jones's discussion of BMC Clinical Pharmacology describes an example of an open peer review process that includes signed review: journals may 'post on the web the entire pre-publication history of the manuscripts accepted for publication. The date the manuscript was received, the reviewer reports and the names of the reviewers as well as the response from the authors and any re- writes of the manuscript are available on-line for all to read. ${ }^{7}$ 
Disclosed review frequently occurs in tandem with editor-mediation. Sumner and Shum's discussion of the Journal of Interactive Media in Education (JIME) surfaces one such example. The journal begins with a closed review process and then moves into a phase of open review.

'This model changes the role of participants in the process to directly involve generating and manipulating argumentation. Reviewers return their comments to the editor in the JIME argumentative format. The editor pulls together all the reviews to seed the argumentative debate. The publisher marks-up the publication and the initial argumentation to include the special cross-tool navigation tags. The article under review and the reviewers' initial comments are then published on the Web, and the review process moves into a phase of open peer review, in which authors, reviewers and readers can engage in debate. The editor then decides whether the article should be accepted, and formulates change requirements for the authors. We also wish to allow for the possibility that interesting discussion threads may arise during the review process which could be distilled into commentaries for publication with the final article. ${ }^{8}$

JIME is an example of editor-mediated, disclosed and crowdsourced review. Similarly, Shakespeare Quarterly's experiments with open peer review mirror JIME's editor-mediated disclosed review process. At Shakespeare Quarterly editors use a hybrid workflow where they pre-select articles, open articles for public peer review, and then move into a closed phase of revisions and final editorial decision-making. ${ }^{9}$

One of the most prominent examples of open peer review in the literature is Atmospheric Chemistry and Physics (ACP). ACP utilizes a review process displaying characteristics of editormediation, crowdsourcing, disclosed review, and transparent review. ACP's editor selects articles to be made available for crowdsourced review and designates referees who submit either attributed or anonymous comments. Community members may also contribute to article review. Crowdsourced comments, reviewer comments, and author responses are published on the web. Following this 
transparent review phase, editors make final editorial decisions regarding publication status. When articles are published, article pre-prints and commentary are published alongside each article's final version. $^{10}$

In addition to current implementations of open peer review, there are also theoretical publication models that display open peer review characteristics. Perakakis et al's model, author-guided peer review, displays post-publication synchronous review characteristics ${ }^{11}$ alongside transparent and crowdsourced review characteristics. Author-guided peer review is completely iterative. In theory, journal articles would no longer remain static. Rather, articles would evolve as research evolves; authors would continually improve their publications using commentary to guide article revisions.

As is evidenced by these examples, open peer review may be simple or complex. While some review processes exhibit one or two open peer review characteristics, others incorporate many.

\section{Discussion}

The literature discusses the many benefits, challenges, and questions that open peer review poses to scholarly publishing communities. In the following discussion I outline benefits and challenges of open peer review, and describe open peer review's significance for scholarly publishing.

\section{Benefits of Open Peer Review}

The literature points to numerous general benefits for authors, reviewers, journals, readers, and scholarly communities resulting from open peer review. Though many of its benefits mirror arguments in favor of open access publishing, it is important not to conflate the benefits resulting from open peer review with those gained from open access publishing.

One of the most similar benefits of open peer review to that of open access publishing is that it generally shortens the time between submission and publication by using pre-print servers and 
crowdsourcing for part or all of a review process. Therefore, science and knowledge progress at a quicker pace. Similarly, both Boldt and Pöschl posit that open peer review enables easier identification of scientific misconduct. ${ }^{12}$ Others suggest that open peer review processes will result in an improvement of the quality of reviews and articles. ${ }^{13}$ Supporting this claim is Bornmann's 2011 study of $\mathrm{ACP}$, which asserts that papers published under its open peer review process show 'top citation performance within their fields. ${ }^{14}$ Along this vein, certain open peer review characteristics, such as crowdsourcing, allow authors to consider plentiful feedback, which $\mathrm{Hu}$, et al, suggest will improve article quality. ${ }^{15}$

Although these benefits are compelling, it is difficult to accept the conclusion that the quality of articles will increase over time. In many areas of scholarship quality is an inherently subjective measure, so there is no way to adequately standardize and measure improvement in quality. Furthermore, using citation performance metrics overlooks a myriad of issues posed by article analytics and bibliometrics.

Another controversial issue related to peer review is that of reviewer abuse and accountability. ${ }^{16}$ On one hand reviewer abuse is enabled by anonymity; on the other hand it is unclear to what extent reviewer abuse is a problem in scholarly publishing. Despite questions of reviewer abuse in blind peer review, open peer review ameliorates any existing or potential problem. By disclosing reviewer identities, reviewers will be held accountable for the quality, content, and professionalism of their reviews by journal editors and the scholarly community. ${ }^{17}$ This also allows for greater transparency of potential conflicts of interest in the peer review process for both editors and reviewers. ${ }^{18}$ Additionally, as reviewers' intellectual contributions to the peer review process are made more visible, these contributions may be held in higher esteem. ${ }^{19}$ Though some argue that visible individual contributions to an open peer review process will be considered for academic promotion and tenure, it will take a much wider adoption and acceptance of open peer review before promotion and tenure committees consider this work on a wide scale. 
Open peer review is also said to strengthen communities of practice. Lipworth and her coauthors observe the practical goals of open peer review are to '...enrich the review process and not to do away with the scientific dimensions. ${ }^{.20}$ Similarly, Maharg and Duncan maintain that open peer review creates dialogue around academic writing in a way that blind review does not. 'Anonymity and the roles of editor as intermediary and judge reduce much of the possible dialogue between author and reviewer. If dialogue is to occur, community is important in setting the boundaries of dialogue. ${ }^{21}$ In essence Maharg \& Duncan suggest that open peer review processes that utilize crowdsourcing or minimal editor mediation work best to create dialogue. While fostering author-reviewer relationships creates a rich review process by enhancing discourse within a community of practice, it is not clear why it would or should be utilized in lieu of editor-mediation. In my own view, editorial mediation remains an important component of scholarly publishing. It ensures consistency in decision-making from journal issue to journal issue. When combining into one process multiple open peer review characteristicseditor-mediation, crowdsourcing, and disclosure - open peer review can enable discussions between reviewers, authors, and an entire community. As such, it strengthens an entire community of practice in a way that traditional peer review cannot.

Friedman, Whitworth and Brownstein introduce a novel concept called extelligence, which is another manner in which open peer review can enrich communities of practice. 'If intelligence is the ability to use one's own mind, then extelligence is the ability to tap into the minds of others in order to generate knowledge collaboratively. ${ }^{22}$ They further posit that extelligence is related to a gift cultureinformation is a gift that, in turn, helps to create new knowledge. As a result '...the author is not only at the receiving end of a decision already taken, but in a position to participate in the review process through interactive means. While reviewing in the traditional model is a solitary activity, the open communicative process may lead to a discourse in which the ideas are refined and shaped. ${ }^{, 23}$ To put it another way, crowdsourced review generates and disseminates new ideas that strengthen communities of practice. In addition to the discussion between reviewers and authors afforded by open peer review, 
readers, too, are presented with more contextual information that enables deeper engagement with the published articles. ${ }^{24}$

The final and most abstract benefit of open peer review is that open peer review helps achieve social justice in scholarly publishing. If we accept the definition of social justice as 'the fair distribution of a society's benefits and burdens among its respective members, ${ }^{25}$ open peer review can be a model to attain social justice in scholarly publishing. While closed peer review systems allow for elitism in peer review practices, Gould argues that open peer review processes challenge elitism and replace it '...with wide-open, robust discussion. ${ }^{26}$ Furthermore, Maharg demonstrates that open peer review processes can flatten the hierarchical nature of closed peer review systems '... where relatively senior academics tend to comment on the work of relatively junior colleagues. ${ }^{27}$ If open peer review is able to flatten hierarchies by challenging and replacing elitism, then it would do a better job of distributing the 'benefits and burdens' of peer review communities than does its traditional peer review counterpart.

Social justice arguments in scholarly publishing also take into account journal publishing economics. For Perakakis et al, open peer review is a step toward eliminating journal monopolies. With open peer review, the authors argue, a scholarly community can select papers and set quality standards, in lieu of publisher monopolies that currently set quality standards. In this argument, Perakakis et al see open peer review as a means to reengage the scientific community, encouraging the community to regain control of its journals and intellectual output.

While I am sympathetic to this argument, it rests on the blanket assumption that journal publishers are not part of a scholarly community. I, on the other hand, maintain that publishers are an important component of scholarly publishing. If authors can utilize and leverage our relationships with journal publishers and push for an "opening up" of peer review practices, publishers may be better able to mediate and implement them.

The benefits of open peer review are wide ranging, benefitting journals, authors, reviewers, and scholarly communities. Open peer review can lead to richer academic discourse and publishing; and 
open peer review journals can attract more agile and risk taking authors, gain readership, and recognition. In addition, open peer review can enhance and ease the project management aspects of peer review. $^{28}$

\section{Challenges of Open Peer Review}

At its heart, the open movement in publishing challenges the roles of publishers, journals, librarians, and the institutions that support them. Since open peer review is closely related to open access publishing, open peer review also challenges scholarly communication's traditional practices. Like any other emerging process, open peer review faces many challenges to adoption and implementation. These challenges are: the changing role of journals and publishers and the overall acceptance of open peer review by the academic community; open peer review's close relationship with open access; and challenges posed by technology.

Paul Uhlir refers to the reinvention of scholarly publishing and a shift in the academic culture as "the intellectual commons. $" 29$ Within this commons some characteristics of open peer review challenge reviewers' roles more than others. For example, crowdsourcing is problematic in that the validity of crowdsourced reviewers' merits could be questioned. ${ }^{30}$ Are crowdsourced reviewers the experts on the topics for the papers undergoing the refereeing process? No matter what implementation or characteristic of open peer review is considered, it will have implications for the roles played by editors, journals, and publishers in academic discourse.

Questioning traditional publishing's roles inherently challenges what we assume about the traditional publishing paradigm. As a result, there is widespread skepticism about open peer review, and many potential authors and referees hesitate to participate. Where referees are concerned about publicly criticizing the work of established scientists, authors may prefer to privately discuss mistakes or flaws of their writing and scholarship. Concerns regarding article quality pervade these hesitations. Despite these concerns, Janowicz and Hitzler's research findings should mitigate them. 
'From our experience so far, both arguments can be rebutted but not completely rejected. The journal has an acceptance rate below $15 \%$, and not a single paper has been accepted in the first round of reviews; i.e., with an "accept as is" decision. Papers from prominent, senior researchers have been rejected. We could not observe an increased tendency to remain anonymous in case of critical reviews. Judging whether open and non-anonymous reviews are of a higher quality is difficult and a recent study points out that no significant difference could be found. ${ }^{31}$

Implementing open peer review processes has also deterred individuals from participating as authors or referees for journals. ${ }^{32}$ As a result of individual hesitation, some open peer review processes - like ACP's — allow referees to remain anonymous. Although allowing anonymity appeases the concerns of hesitant reviewers, it is a hindrance to the implementation of fully open peer review, which relies on identity disclosure. Allowing anonymity may be a good intermediate step as scholarly communities experiment with open peer review, though in the long run it should be phased out as scholars more readily accept open peer review. Additionally, authors may be fearful of the 'perceived risk' they take when exposing their work to a large audience via pre-print servers for crowdsourced reviewing, or even publishing drafts with the final versions of articles. ${ }^{33}$ Articles undergoing a crowdsourced review process may not garner any reviews, and scholarly 'cliquishness' might be made apparent. ${ }^{34}$ In this case, Nentwich argues, open peer review reveals tensions between scholarly camps. Author and reviewer hesitation to participate in open peer review points to a larger and related problem: scholars' and publishers' acceptance of open peer review may not advance until they more widely accept and adopt open access publishing practices. While some disciplines have accepted open access publishing, many have not. Open peer review, which is very much part of the open ethos, therefore falls victim to negative attitudes toward open access publishing. While in the long term open access and open peer review go hand in hand, open peer review does not need to occur only in open access journals. What defines open peer review, disclosure of author and reviewer identities, in no way 
relies on the free and open publication of articles. Although scholarly publishing's culture is slowly changing, open peer review is a larger and further step into the frightening world of changing scholarly publishing models.

Technology could greatly enhance the ability to implement open peer review, but 'at present, there is hardly any software support for the editorial management of open and transparent review processes by existing journal management systems or content management systems. ${ }^{35}$ Because most open peer review processes are technologically mediated, technical challenges, software inefficiencies, and bugs may negatively affect the efficacy, implementation, and adoption of open peer review. In some implementations tracking numerous article versions proves difficult. When authors cite multiple versions of articles a journal's impact factor or other similar measures may become inflated. ${ }^{36}$ Moreover, the article submission and review process in technological environments demands clear instructions and training. ${ }^{37}$ While using technology may result in a need for reviewers to be further trained in the social aspects of reviewing, Lipworth asserts,

'In practice, this would require that existing training and guidance for reviewers and editors retain "scientific" components, while at the same time taking a more critically informed approach to "science" (as outlined in innumerable existing guidelines on the critique of scientific research) and taking account of the social values of those engaged in the review process. ${ }^{.38}$

Open peer review's relationship to technology is analogous to its relationship with open access. Theoretically, open peer review does not rely on the existence of any particular technology (aside from the ability to communicate with the written word); however, it has come to be seen as inextricably linked to technological systems that enable it. This techno-deterministic thinking regarding open peer review may harm its progress. While technology is a means to conduct open peer review, open peer review should first be considered and accepted by scholarly communities on a theoretical level, before any technological implementation of open peer review is to fully succeed. At its core open peer review 
requires nothing more than disclosure of the author's and reviewer's identities.

\section{Conclusion}

In this literature review I have revealed common characteristics of open peer review and discussed open peer review's many benefits and challenges. Among these challenges are the divergent approaches and values tied to open peer review. Scholarly and publishing communities would benefit if we could develop a consensus around an understanding of open peer review's definitions and models. A shared understanding of open peer review would facilitate clearer communication regarding its benefits, challenges, and emerging issues.

Despite current techno-deterministic thinking, scholarly publishing communities should not rely on technology to implement open peer review, since open peer review can be as simple as disclosing author and reviewer identities. Although it challenges journals', publishers', and editors' roles, open peer review in scholarly publishing should retain editorial mediation. Technology can ease the coordination of an open peer review process; however, open peer review concerns scholarly discourse, publishing, and discussion, rather than the technology that enables it.

Researchers should explore the existing models of open peer review to follow up on the characteristics outlined in this article. In order to better understand and capture disciplinary differences in opened review and publishing practices, this research should investigate open peer review as it is practiced within individual disciplines. Other research should test the validity of claims regarding article and review quality, and explore how open peer review could best fit into the academic promotion and tenure process. As open peer review experiments and implementations grow in numbers, article demographics should continue to be documented and reported.

Finally, as scholarly publishing continues to change, so, too, will peer review practices. Scholarly publishing communities will continue to discuss opening up peer review practices, and at the same time these communities will continue to explore, test, and evaluate open peer review. 
$1 \quad$ McGiffert, Michael. 'Is Justice Blind? An Inquiry into Peer Review.' Scholarly Publishing 20, 1 (1988): 43-48.

2 Sumner, Tamara, and Simon Buckingham Shum. 'Open Peer Review \& Argumentation: Loosening the Paper Chains on Journals.' Ariadne (1996): n. page.

3 McCormack, Nancy. 'Peer Review and Legal Publishing: What Law Librarians Need to Know About Open, SingleBlind, and Double-Blind Reviewing.' Law Library Journal 101, 1 (2009): 59-70, 4

4 Mulligan, Adrian. 'Quality, Certification and Peer Review.' Information Services \& Use 28 (2008): 197-214, 202

5 Ware, Mark. 'Peer Review: Recent Experience and Future Directions.' New Review of Information Networking 16, 1 (2011): $23-53,25$

6 Shotton, David. 'The Five Stars of Online Journal Articles -a Framework for Article Evaluation.' D-Lib Magazine 18, 1/2 (2012): 6

7 Jones, Alan Wayne. 'The Distribution of Forensic Journals, Reflections on Authorship Practices, Peer-review and Role of the Impact Factor.' Forensic Science International 165, 2-3 (2007): 115-28, 122

8 Sumner \& Shum, 'Open Peer Review \& Argumentation,' Para. 9

$9 \quad$ Fitzpatrick, Kathleen, and Katherine Rowe. 'Keywords for Open Peer Review.' Logos 21, 3-4 (2010): 133-141, 136

10 Pöschl, Ulrich. 'Interactive Open Access Peer Review: The Atmospheric Chemistry and Physics Model.' Against the Grain 21, 3 (2009): 26-32.

11 Perakakis, Pandelis et al. 'Natural Selection of Academic Papers.' Scientometrics 85, 2 (2010): 553-559.

12 Boldt, Axel. 'Extending ArXiv.org to Achieve Open Peer Review and Publishing.' Journal of Scholarly Publishing 42, 2 (2011): 238-242; Pöschl, 'Interactive Open Access Peer Review'

13 Prug, Toni. 'Open-process Academic Publishing.' Ephemera: Theory \& Politics in Organization 10, 1 (2010): 40-63; and Boldt, 'Extending ArXiv.org to Achieve Open Peer Review and Publishing'

14 Bornmann, Lutz et al. 'Is Interactive Open Access Publishing Able to Identify High-Impact Submissions? A Study on the Predictive Validity of Atmospheric Chemistry and Physics by Using Percentile Rank Classes.' Joumal of the American Society for Information Science and Technology 62, 1 (2011): 61-71, 69

15 Hu, Changping, Yaokun Zhang, and Guo Chen. 'Exploring a New Model for Preprint Server: A Case Study of CSPO.' Joumal of Academic Librarianship 36, 3 (2010): 257-262

16 Cope, B, and M Kalantzis. 'Signs of Epistemic Disruption: Transformations in the Knowledge System of the Academic Journal.' First Monday 14, 4-6 (2009); Fitzpatrick, Kathleen. 'Peer-to-peer Review and the Future of 
Scholarly Authority.' Social Epistemology 24, 3 (2010): 161-179.; Mulligan, Adrian. 'Peer Review in a Changing World - Preliminary Findings of a Global Study.' Serials: The Journal for the Serials 23 March (2010): 25-34; and Perakakis, 'Natural Selection of Academic Papers'

17 Cope \& Kalantzis, 'Signs of Epistemic Disruption'; Fitzpatrick, 'Peer-to-peer review and the future of scholarly authority'; and Mulligan, 'Quality, Certification and Peer Review'

18 Janowicz, Krzysztof, and Pascal Hitzler. 'Open and Transparent: The Review Process of the Semantic Web Journal.' Learned Publishing 25, 1 (2012): 48-55

19 Boldt, 'Extending ArXiv.org to Achieve Open Peer Review and Publishing'; Bornmann, Lutz et al. 'From Black Box to White Box at Open Access Journals: Predictive Validity of Manuscript Reviewing and Editorial Decisions at Atmospheric Chemistry and Physics.' Research Evaluation 19, 2 (2010): 105-118; and Fitzpatrick, 'Peer-to-peer review and the future of scholarly authority'

20 Lipworth, Wendy et al. 'Should Biomedical Publishing Be "Opened Up"? Toward a Values-Based Peer-Review Process.' Bioethical Inquiry 8, 3 (2011): 267-280, 278

21 Maharg, Paul, and Nigel Duncan. 'Black Box, Pandora's Box or Virtual Toolbox? An Experiment in a Journal's Transparent Peer Review on the Web.' International Review of Law, Computers \& Technology 21, 2 (2007): 109-128, 111

22 Friedman, Robert, Brian Whitworth, and Michael Brownstein. 'Realizing the Power of Extelligence: ANew Business Model for Academic Publishing.' International Joumal of Technology, Knowledge \& Society 6, 2 (2010): 105-117, 106

23 Nentwich, Michael. 'Quality Control in Academic Publishing: Challenges in the Age of Cyberscience.' Poiesis \& Praxis 3, 3 (2005): 181-198, 183

24 Fitzpatrick, 'Peer-to-peer review and the future of scholarly authority'

25 Erickson, Patricia E. 'Social Justice,' in K. Christensen and D. Levinson, eds., Encyclopedia of Community: From the Village to the Virtual World (Thousand Oaks, CA: SAGE Publications, Inc., 2003): 1310-15.

26 Gould, Thomas H.P. P. 'Scholar as E-Publisher: The Future Role of [anonymous] Peer Review within Online Publishing.' Joumal of Scholarly Publishing 41, 4 (2010): 428-448, 442

27 Maharg \& Duncan, 'Black Box, Pandora's Box or Virtual Toolbox?'

28 Prug, 'Open-process academic publishing'

29 Uhlir, Paul F. 'Re-intermediation in the Republic of Science: Moving from Intellectual Property to Intellectual 
Commons.' Information Services \& Use 23, 2/3 (2003): 63

30 Nentwich, 'Quality Control in Academic Publishing'

31 Janowicz \& Hitzler, 'Open and Transparent,' 53-54.

32 Fitzpatrick \& Rowe, 'Keywords for Open Peer Review'

33 Sumner \& Shum, 'Open peer review and Argumentation'

34 Nentwich, 'Quality Control in Academic Publishing,' citing Tomlins, 184

35 Janowicz \& Hitzler, 'Open and Transparent,' 53

36 Bornmann, 'Is Interactive Open Access Publishing Able to Identify High-Impact Submissions?'

37 Fitzpatrick \& Rowe, 'Keywords for Open Peer Review'

38 Lipworth, 'Should Biomedical Publishing be Opened Up?' 729 